\title{
AC 2011-1805: USING GEARSET TO PROMOTE STUDENT AWARENESS OF LEARNING OBJECTIVES
}

David R. Bowman, Clemson University

David R. Bowman is a Lecturer in the General Engineering Program at Clemson University. His educational background includes a B.S. and M.S. in Computer Engineering from Clemson University.

Elizabeth A. Stephan, Clemson University

(C)American Society for Engineering Education, 2011 


\section{Using GEARSET to Promote Student Awareness of Learning Objectives}

In fall 2009, several new grade reporting modules were added to GEO (General Engineering Online), a web based class management tool developed at Clemson University for use with large enrollment freshman engineering courses. The dynamic grade report module provided a live record of attendance and course grades, capabilities for feedback on assignments from instructors to students, and performance predictions to give students perspective on the grades necessary to earn a particular final grade in the course. The implementation of this module led to significant improvements on student evaluation of all instructors using GEO, specifically on questions regarding student satisfaction with being informed of their progress throughout the course. These observations lead to our desire to implement new modules in GEO to further improve student satisfaction and engagement in academic material.

Some of the most troubling comments on our instructor evaluations were related to students' perception of a disconnect between the learning activities and the learning objectives. One of the many purposes of writing learning objectives is to establish expectations of content and performance between students and instructors. To address this, we developed a new module called GEARSET (General Engineering Assessment Record Self Evaluation Tool) with the intent to bridge the gap between student understanding of the relationship between learning activities and the course learning objectives. Functionally, GEARSET allows students to track their own progress of the required and recommended elements of study for a course. In addition, GEARSET displays daily, unit and overall course learning objectives in an interface that allows the student to self-evaluate their understanding by "checking off" their progress. For the instructor, GEARSET allows tracking of assignment completion and self-evaluation of learning objectives. This paper gives an overview of GEARSET, discusses the integration within first year engineering courses, addresses how it can be used by students as a tool for self-evaluation, and how use of GEARSET by instructors provides greater insight into student progress.

\section{Background}

Many introductory engineering courses use web based tools like Blackboard ${ }^{1}$ or Moodle ${ }^{2}$ to facilitate course management. At many large engineering schools, first year courses often have very large enrollments, and multiple papers ${ }^{3}$ have been published discussing the short comings of these online systems with large classes, especially when taught by multiple instructors. Many of these issues, especially in file submission, grade reporting, event management, and teaming led to the development of the first version of $\mathrm{GEO}^{4}$ at Clemson University in the General Engineering Program. After these modules were improved to become more robust, we observed significant improvement on Clemson's common end-of-semester instructor evaluations, especially on areas related to notification of student progress throughout the semester. This observation, along with positive student feedback about GEO, led to interest in new feature development, specifically to position GEO as a rich pedagogical complement to large enrollment, active learning engineering courses. The difference between common course management tools and GEO is GEO's emphasis on communication (team and individual), personalized feedback, and simplification of the user interface for students and instructors managing the course. 
At the same time as new module development in GEO, several faculty members in the General Engineering Program began revising our course materials into textbook format, including a revision of the overall learning objectives for each course, the units of study within each course, and the topics presented within each unit of study. These learning objectives were all intentionally laid out to map directly to ABET's Criterion 3 Program Objectives for Accrediting Engineering Programs 5 . While it may be clear to educators why certain topics, units, or courses may be important and feed directly into engineering success, we noticed some of our students did not understand the relationship between the course learning objectives and specific activities throughout the semester. In particular, comments on our instructor evaluations made it clear that students did not quite see the value of the material taught in some of our classes:

- "I doubt I will ever use anything like this consistently as a mechanical engineer... electrical and computer engineers know code because it is their job."

- "...the course material seems irrelevant to almost every major required to take this class... just another 'weed-out' class."

While these comments represent a small minority of our class, they are concerning due to the fundamental nature of the material presented in our first year courses. As a result, we saw a need for a tool that forced students to reflect upon the material and think how each action they take in our class translates directly into mastery of objectives within each section, within a unit of study, and within a first year engineering course. Given student satisfaction with GEO, we thought it would be powerful to include this tool.

\section{GEARSET: General Engineering Assessment Record Self Evaluation Tool}

As a first step to developing this tool, we began by creating a map from ABET Engineering Program criteria to our course objectives. In each course, we mapped the course objectives to each unit of instruction and specific objectives that represent mastery within each topic, as shown in a sample in Figure 1. The goal of this map is to help students discover the connections between each topic presented in the class and see how it relates to the broader objectives of studying engineering.

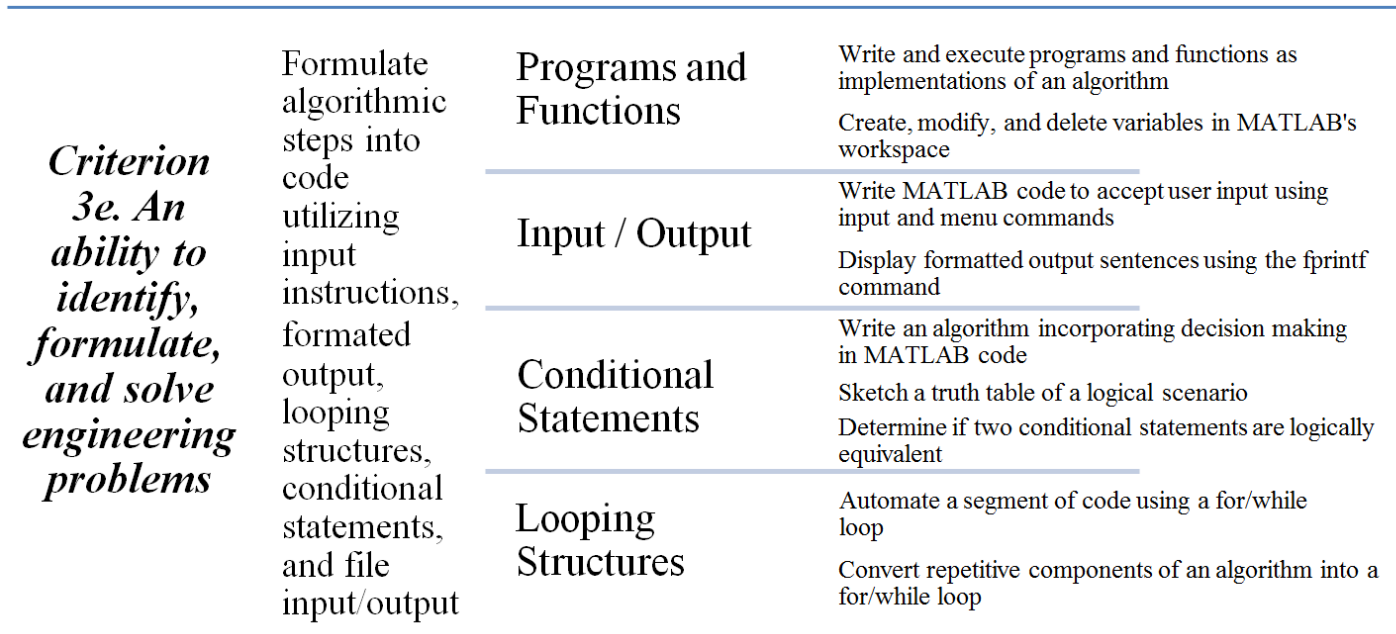

Figure 1: A sample mapping from an ABET Criterion (left), to one course objective, to different units of study, to specific objectives that define mastery of that unit of study (right.) 
The next phase of tool development was considering different delivery mechanisms for increasing student awareness of both the specific and broader objectives of the course. Like any engineering course, our students are provided with adequate materials in and out of class to guide their inquiry in each unit of study. For all subjects, we provide online lectures, recommended problems, and recommended reading to complement the activities in the classroom. Since there are so many different resources available for students, we thought it would be helpful to present those opportunities to students embedded within a list of the course, unit, and section learning objectives.

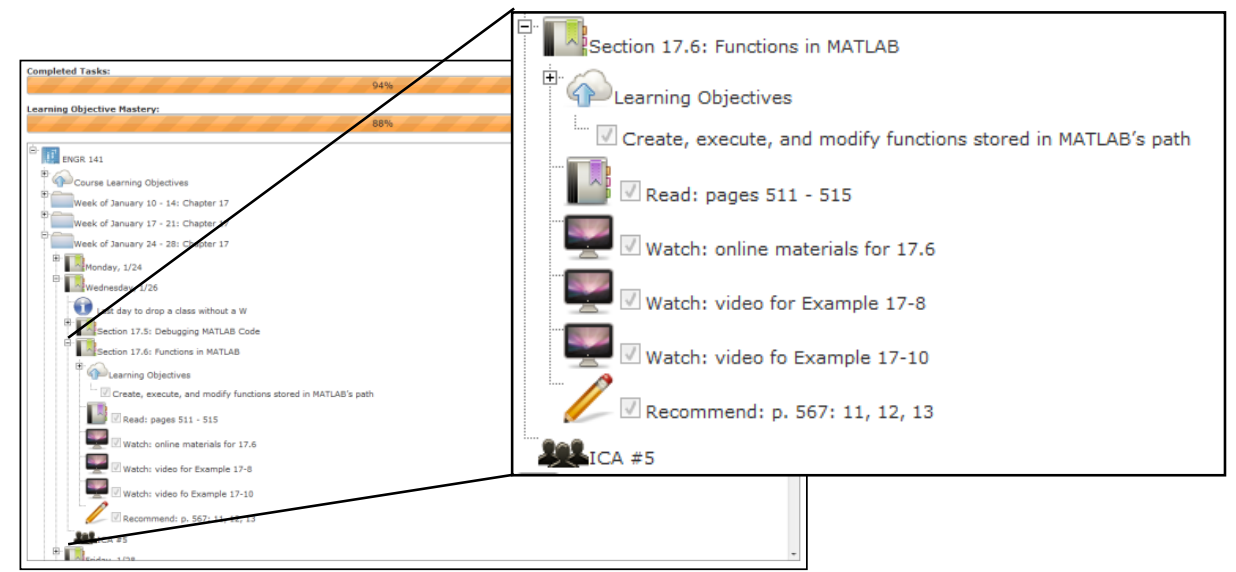

Figure 2: The main student GEARSET interface in GEO.

To do this, we created GEARSET as a web-based module in GEO (Figure 2) written in PHP with heavy use of JQuery UI framework ${ }^{7}$ and AJAX (asynchronous JavaScript and XML) functionality. The goal was to create a self-evaluation tool for students to use like a "to-do" list that displays all of the tasks instructors recommend in order for the student to build mastery of a subject. As soon as a student completes a task, they click a checkbox in GEARSET and the task progress bar increases. At any time, students are able to load GEARSET to see exactly how much effort they have put into the course with respect to all of the resources provided by their instructor. In addition, the learning objectives are presented as clickable checkboxes so students can record exactly when they feel they have mastered a particular subject. When a student clicks a checkbox, GEO stores a record of their completion in a $\mathrm{MySQL}^{8}$ database, including a student identifier, a date-time stamp to indicate exactly when the box was clicked, and an identifier that codes exactly which task or objective box was clicked.

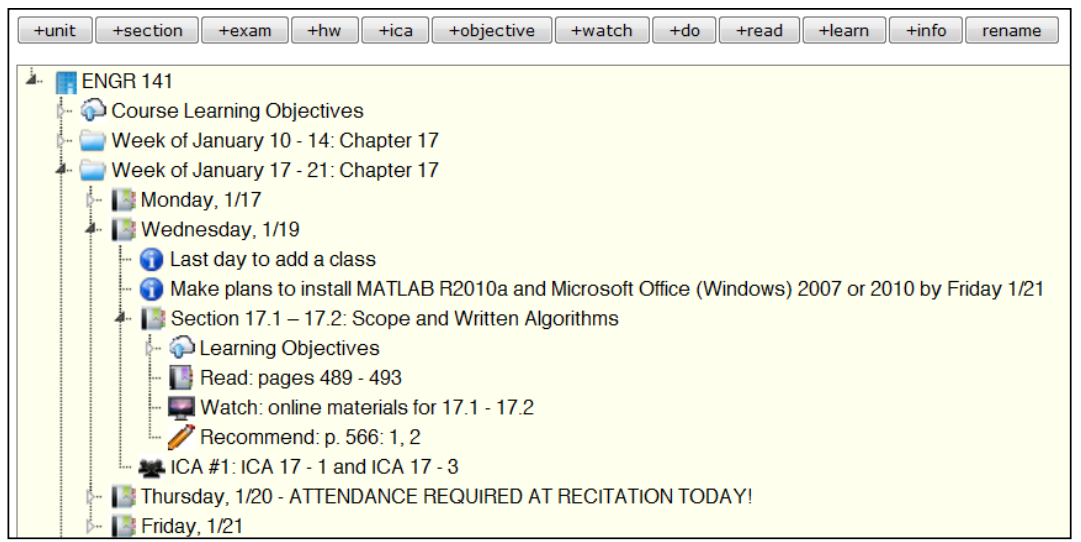

Figure 3: GEARSET authoring interface. 
For instructors, GEARSET contains a suite of tools to develop a set of objectives and activities, as well as to view data generated by the system. The authoring tool (Figure 3) allows instructors to quickly add different types of activities or objectives and arrange them into folders or sections using a drag-and-drop interface. In addition, each instructor can view the individual GEARSET interface for each student enrolled in the course to observe the out of class preparation by that student. To examine objective and activity levels for an entire class, two different tools were created to give instructors insight to the status of their class at any given time. One report allows the instructor to select a major unit of study and look at the activities and learning objectives contained within that unit. As shown in Figure 4 (top), instructors gain a real time perspective on exactly how much activity is going on with their students based on their GEARSET usage. A second report allows instructors to view a detailed report on individual activities or objectives to see who clicked, when they clicked, and compare that specific activity to an actual assignment. In addition to a click log, a graph showing when students clicked a check box is automatically generated and displayed on the report. In Figure 4 (bottom), a sample report shows the student reported mastery of logic and conditionals in this course, with respect to an assignment related to the topic.

Do:
\begin{tabular}{|c|c|}
\hline Description: & Status: \\
\hline Recommend: p. $566: 3,4,5,6$ [details] & $83 \%$ \\
\hline Reccomend: p. $566: 7,8 ;$ p. $567: 10$ [details] & $77 \%$ \\
\hline
\end{tabular}

Read:
\begin{tabular}{|c|c|}
\hline Description: & \multicolumn{2}{|c|}{ Status: } \\
\hline Read: pages $493-498$ [details] & $97 \%$ \\
\hline Read: pages $498-509$ [details] & $96 \%$ \\
\hline
\end{tabular}

Watch:
\begin{tabular}{|c|c|}
\hline Description: & Status: \\
\hline Watch: online materials for 17.3 [details] & $88 \%$ \\
\hline Watch: online materials for 17.5 [details] & $85 \%$ \\
\hline
\end{tabular}

In Class Activities: ICA 13 / 'Read: pages 540 - 548' Performance Analysis

- Average (clicked): $83(n=104)$

- Average (no click): 78 ( $n=66)$

\section{Click Log:}

\begin{tabular}{|c|c|}
\hline Username: & Datetime: \\
\hline Student A & $02 / 0211: 41 \mathrm{am}$ \\
\hline Student B & $02 / 0711: 28 \mathrm{am}$ \\
\hline Student C & $02 / 0911: 16 \mathrm{am}$ \\
\hline Student D & $02 / 105: 34 \mathrm{pm}$ \\
\hline
\end{tabular}

Read: pages 540 - 548

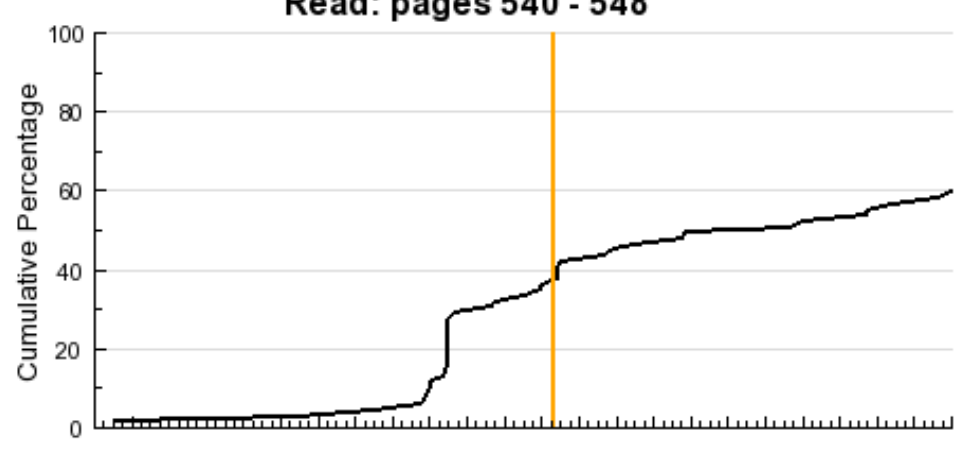

Figure 4: Sample reports generated by GEARSET. (top) A view of the completion record for each learning activity and objective for an entire section. (bottom) A detailed view of a specific learning objective compared with an assignment (ICA 13).

In fall 2010, GEARSET was adopted by three different first year engineering courses and presented as a non-required, but helpful tool for students to use throughout the semester. 
Different sets of objectives and activities were created using the GEARSET authoring tool for these courses by the instructors teaching the class, but the categories of activities remained similar across all three courses - required reading, viewing online material, recommended problems, in-class activities, and homework. During the first week of class, instructors of these courses did a demonstration of how students could use GEO to keep track of their course activities and provided similar instructions electronically for students to use a reference throughout the semester. For the remainder of this paper, preliminary results from two of the three first year engineering courses adopting GEARSET are presented. The course not presented here had a lower student enrollment $(n=32)$, so it was not used in the analysis of data presented in this paper.

Preliminary Results and Discussion

As of fall 2010, we have successfully launched the GEARSET module in GEO in three different courses involving approximately 475 students. In each course, GEARSET was presented as a non-required tool to help students throughout the semester. During fall $2010,97.5 \%$ of the students enrolled in the courses generated over 61,000 clicks on learning objectives and activities. In addition, many students made very positive comments about GEARSET on final instructor evaluations, so it was clear that the initial launch was a success. Some comments included:

- "The organization with GEARSET was crucial with the amount of work in this class."

- "The GEARSET was awesome. Most people in other classes struggled to stay organized."

- "GEARSET was great. The only thing that would make it better is if dates were attached to the objectives as well."

- "I liked how GEARSET made it easy to keep up with our grades and assignments."

Table 1 summarizes the average click percentages broken down by the type of activity/learning objective compared to the final grade the student earned in two courses that used GEARSET. The "activities" checkbox grouping included recommended problems to work out of class, as well as a checkbox for each homework and in-class activity. Even though they completed them, many students did not check off in-class activities or homework assignments as frequently as they checked off recommended out of class activities, so those items were modified to be nonclickable information items in the spring 2011 edition of GEARSET. Furthermore, it became evident that we were lacking information on the number of times students viewed GEARSET if they didn't click any boxes, so a modification to the code for spring 2011 will allow us to track the number times students view the page. The overall learning activity completion statistics provide important feedback to the instructor about which components lend themselves toward student success.

Table 2 summarizes the overall click statistics for two of the engineering courses in the first semester of adoption. In all courses, "A" students clicked checkboxes in GEARSET approximately once per week and students who ended the semester with an F clicked checkboxes in GEARSET approximately every two weeks. In both courses, " $B$ " and " $C$ " students generated a large number of consecutive clicks, or "click bursts," revealing that these students were not 
paying as close attention to GEARSET as the "A" students. The "click burst" phenomena also occurred with a few failing students in ENGR 141, but was less common with "A" students in both courses. This indicates that GEARSET behavior can be used as an early warning mechanism to alert instructors of students who may be at risk of earning a failing grade in a course. In addition, the GEARSET activity data may also provide valuable evidence for the strength of class activities, reading assignments, or supplemental online material.

\begin{tabular}{|c|c|c|c|c|}
\cline { 2 - 5 } \multicolumn{1}{c|}{ CES 102} & Learning Objectives & Reading & Online Videos & $\begin{array}{c}\text { Other } \\
\text { Activities }\end{array}$ \\
\hline A $(\mathrm{n}=94)$ & $61.5 \%$ & $63.0 \%$ & $56.3 \%$ & $55.5 \%$ \\
\hline B or C $(\mathrm{n}=244)$ & $52.2 \%$ & $52.8 \%$ & $47.0 \%$ & $48.5 \%$ \\
\hline D or F $(\mathrm{n}=13)$ & $21.4 \%$ & $21.9 \%$ & $16.4 \%$ & $22.6 \%$ \\
\hline ENGR 141 & Learning Objectives & Reading & Online Videos & $\begin{array}{c}\text { Other } \\
\text { Activities }\end{array}$ \\
\hline A $(\mathrm{n}=23)$ & $75.4 \%$ & $86.6 \%$ & $78.5 \%$ & $68.2 \%$ \\
\hline B or C $(\mathrm{n}=42)$ & $64.7 \%$ & $81.0 \%$ & $66.1 \%$ & $54.5 \%$ \\
\hline D or F $(\mathrm{n}=14)$ & $57.1 \%$ & $75.0 \%$ & $62.3 \%$ & $46.5 \%$ \\
\hline
\end{tabular}

Table 1: The average percentage of checkboxes clicked by students earning different grades in first year engineering courses.

\begin{tabular}{|c|c|c|c|}
\cline { 2 - 4 } \multicolumn{1}{c|}{ CES 102 } & $\begin{array}{c}\text { Mean no. clicks per } \\
\text { class meeting }\end{array}$ & $\begin{array}{c}\text { Mean no. } \\
\text { clicks per use }\end{array}$ & $\begin{array}{c}\text { Mean no. days with } \\
\text { a click in } \\
\text { GEARSET }\end{array}$ \\
\hline A $(\mathrm{n}=94)$ & 3.8 & 10.9 & 16.5 \\
\hline B or C $(\mathrm{n}=244)$ & 3.2 & 12.5 & 12.5 \\
\hline D or F $(\mathrm{n}=13)$ & 1.4 & 7.9 & 7.9 \\
\hline Expected Value & $\mathbf{8 . 2}$ & $\mathbf{8 . 2}$ & $\mathbf{3 5}$ \\
\hline ENGR 141 & $\begin{array}{c}\text { Mean no. clicks per } \\
\text { class meeting }\end{array}$ & $\begin{array}{c}\text { Mean no. } \\
\text { clicks per use }\end{array}$ & $\begin{array}{c}\text { Mean no. days with } \\
\text { a click in } \\
\text { GEARSET }\end{array}$ \\
\hline A $(\mathrm{n}=23)$ & 2.7 & 6.6 & 15.6 \\
\hline B or $\mathbf{C}(\mathrm{n}=42)$ & 2.3 & 9.5 & 10.0 \\
\hline D or F $(\mathrm{n}=14)$ & 2.0 & 9.1 & 9.1 \\
\hline Expected Value & $\mathbf{3 . 7}$ & $\mathbf{3 . 7}$ & $\mathbf{3 0}$ \\
\hline
\end{tabular}

Table 2: Overall click statistics on checkboxes clicked by students earning different grades in first year engineering courses: mean number of clicks class (\# clicks / \# class meetings with clickable items: CES $102=35$ days, ENGR 141 = 30 days), the mean number of clicks by each student in each GEARSET usage, mean number of days with a recorded click in GEARSET (does not include number of views). The expected mean number of clicks were computed by dividing the total number of clickable items in each course by the total number of meeting days. 


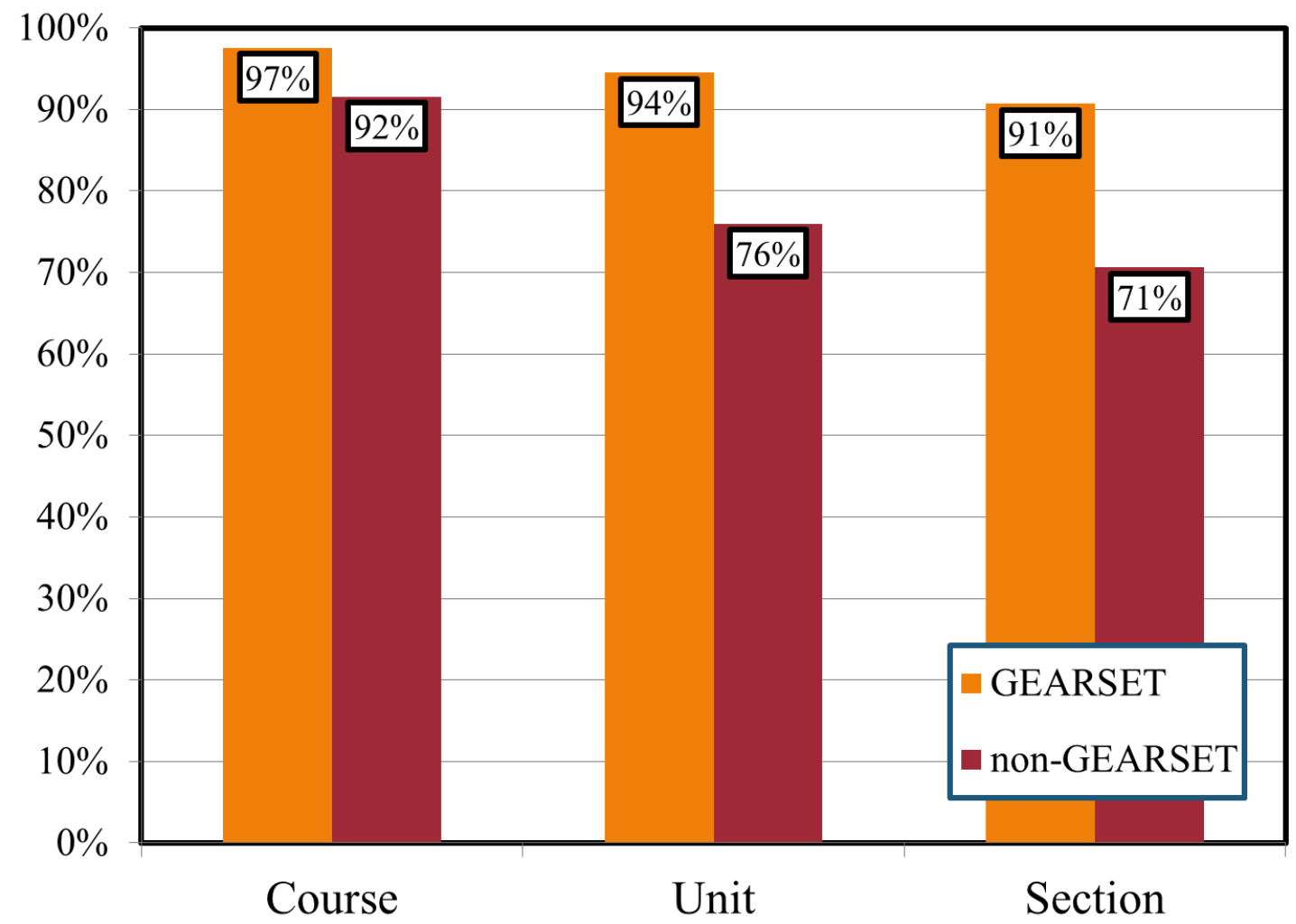

Figure 5: Responses to question "My instructor gave me a list of objectives" after the first semester of use.

In order to determine whether student perception of the relationship between learning activities and the course learning objectives were improved in the group adopting GEARSET, we asked each student at the end of the semester to answer the question "my instructor gave me a list of objectives", which included course, unit, and section objectives. Every student was provided with a list of course, unit, and section learning objectives, so theoretically, these should all be $100 \%$. In GEARSET, these objectives were provided electronically each time the student used GEARSET. In the non-GEARSET courses, the objectives were provided on paper once at the beginning of the semester or the start of each unit. As seen in Figure 5, 90\% the users in GEARSET were aware of the course, unit and section objectives, but the non-GEARSET users were less aware of the unit and section objectives.

\section{Conclusion and Future Work}

In conclusion, the results presented Figure 5 does indicate that use of GEARSET improves awareness of the different types of learning objectives in our courses, however preliminary results of the development and integration of GEARSET in the classroom reveal the need for further investigation of the click-log data to gain insight into specifically which activities contribute to obtaining mastery of specific learning objectives. In addition, the GEARSET data may aid in investigating class preparation behavior patterns of successful students in order to pass that knowledge down to future first year engineering students. 
A recent modification to GEO allows instructors to create, edit, and apply rubrics directly in the electronic grade book so that the students receive detailed electronic feedback on each assignment in their grade report. The rubric data, in concert with the GEARSET data, position GEO to further become a tool for providing rich and specific personalized feedback and recommendations for individual student improvement.

\section{Bibliographic Information}

${ }^{1}$ Blackboard, http://www.blackboard.com/, Retrieved January 16, 2011.

${ }^{2}$ Moodle, http://moodle.org/, Retrieved January 16, 2011.

${ }^{3}$ Lo, J. et al. Blackboard Collaboration: Consolidation of On-Line Course Materials and Assessment for Multiple Sections Using Blackboard, Proceedings of the 2004 American Society for Engineering Education Annual Conference and Exposition.

${ }^{4}$ Bowman, D. et al. GEO: A Web-Based Event Registration and Communication Tool, Proceedings of the 2008 American Society for Engineering Education Annual Conference and Exposition.

${ }^{5}$ ABET. Criteria for Accrediting Engineering Programs - Effective for Evaluations during the 2010-2011 Accreditation Cycle. http://www.abet.org/forms.shtml, Retrieved January 16, 2011.

${ }^{6}$ PHP, http://www.php.net/, Retrieved January 16, 2011.

${ }^{7}$ jQuery UI, http://jqueryui.com/, Retrieved January 16, 2011.

${ }^{8}$ MySQL, http://www.mysql.com/, Retrieved January 16, 2011. 